\title{
Industrial applications of modelling tools to simulate the PAMCHR casting and VAR process for Ti64
}

\author{
Emiliane Doridot ${ }^{1}$, Stéphane Hans ${ }^{1}$, Alain Jardy ${ }^{2}$, Jean-Pierre Bellot ${ }^{2}$ \\ ${ }^{1}$ Aubert et Duval, Les Ancizes, France \\ ${ }^{2}$ Institut Jean Lamour, Nancy, France
}

The PAMCHR (Plasma Arc Melting Cold Hearth Refining) process followed by a VAR (Vacuum Arc Remelting) melting is used to recycle Ti64 scrap for aeronautical applications. The produced ingot quality is linked to the quality of charging materials and to numerous operating parameters. Ecotitanium (a company created by UKAD, a joint-venture between Aubert \& Duval and UKTMP, ADEME and Crédit Agricole Centre France) launched a program with the Institut Jean Lamour dedicated to the development of specific modelling tools in order to get a better understanding of operating parameters effect on the final ingot quality. A model of the PAMCHR casting was developed and used to describe the heat transfer, liquid metal flow and alloying elements behavior during mixing in the liquid pool followed by segregation during solidification. The effect of PAMCHR electrode composition on the final VAR ingot composition is also studied using the SOLAR VAR model. Model validation by comparison with industrial ingots is presented with some examples of operating parameters sensitivity study.

\section{Introduction}

Ecotitanium is a new facility built in 2017 in Saint Georges de Mons (France) dedicated to the production of aeronautical quality titanium grade ingots by recycling turnings and solid reverts. It is part of an integrated production chain comprising Ti sponge and titanium ingot production (UKTMP), billet forging (UKAD) and bar rolling (A\&D), machining (MKAD) and finally scrap recycling at Ecotitanium by PAMCHR (Plasma Arc Melting Cold hearth Refining) followed by a final VAR (Vacuum Arc Remelting). Schematics of the melting processes can be seen on Figure 1.

In order to get a better understanding of operating parameters effects of both PAMCHR and VAR on the final ingot quality, EcoTitanium and Aubert \& Duval have launched with the Institut Jean Lamour a program to develop specific modelling tools. It includes a PAMCHR cold hearth model [1] and a PAMCHR casting model which can be coupled with the SOLAR (SOLidification during Arc Remelting)VAR model also developed by IJL. Defect-free and chemical homogeneity are key criteria for final ingot quality. The PAMCHR cold hearth model purpose is to study the effect of melt rate and torches power distribution on defect removal mechanism. The development of this model is on-going and some first results can be found in [1].

The PAMCHR ingot casting model describes heat transfer, liquid metal flow and alloying elements behavior during mixing in the liquid pool followed by segregation during solidification. Effect of operating parameters such as casting rate, casting torch power and input material composition can be evaluated. Additionally, the SOLAR VAR model can be used to study the effect of the remelting conditions on the final VAR ingot quality.

The SOLAR VAR model was already extensively used and validated to describe Ti alloy solidification and liquid pool shape [2]. Additionally, a full scale industrial PAM ingot was produced and the as-cast structure analyzed in order to validate the liquid pool prediction of the PAM casting model (PAMELA, which stands for Plasma Arc Melting or ELectron beam refining with Annulus mold). In order to accurately predict alloying element segregation during solidification of Ti64, several industrial VAR test ingots were analyzed and compared to the macrosegregation prediction.

For Titanium recycling, oxygen content in the charge has to be carefully managed as some pick-up can be linked with turnings and solid reverts. Hence chemistry is adjusted by blending recycled materials with Titanium sponge and master-alloys. If the chemical homogeneity of the melt is mainly linked to the charge composition, the PAM casting and VAR remelting conditions can help minimizing any alloying element variation by mixing in the liquid pool. This behavior was studied using the developed PAM and VAR models.

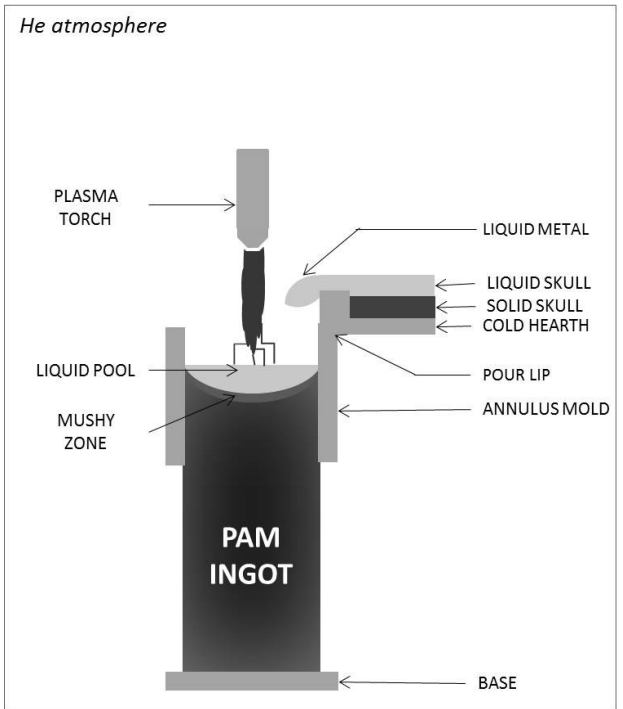

Plasma Arc Melting

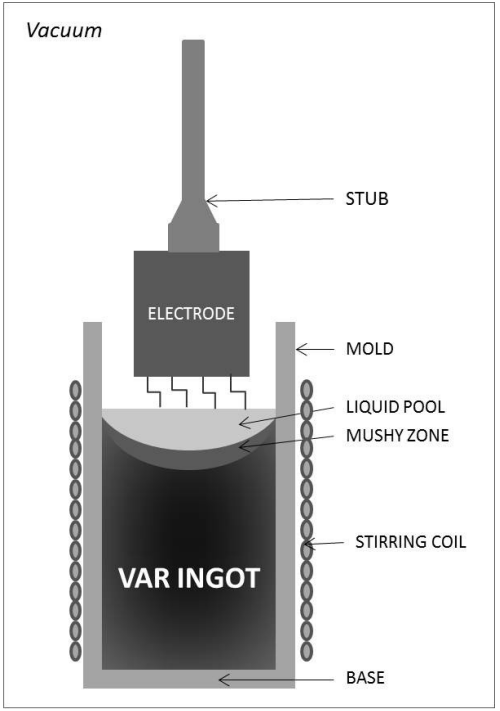

Vacuum Arc Remelting

Figure 1 EcoTitanium processes (PAMCHR and VAR) 


\section{PAMCHR casting and VAR Model}

The first version of the VAR model SOLAR was applied to the simulation of Ti remelting [3], then the model was adapted to simulate the remelting of steels, Ni-based superalloys and $\mathrm{Zr}$ alloys [4] [5] [6]. In all cases, the purpose of the model is the numerical simulation of the whole VAR processing route, with the ultimate aim of process optimization. The modelling of PAMCHR casting was achieved more recently. The PAMELA model was derived from the SOLAR code, while accounting for the process operating conditions through the set-up of appropriate boundary conditions.

Based on the numerical solution of a set of partial differential equations which represent the real physical phenomena, PAMELA and SOLAR make it possible to describe electromagnetism, fluid flow, heat transfer, phase change and solute transfer during the growth and solidification of the PAM or VAR ingot. This enables directly to relate the melting parameters to the melt pool profile, hydrodynamic behavior of the liquid metal, local solidification conditions and chemical segregation in the secondary ingot. An important feature of the model is its ability to simulate an actual processing route having either 2 or 3 successive VAR melts or PAMCHR followed by VAR, using the heterogeneous ingot obtained from the preceding operation as a VAR electrode.

Because of space limitations, it is not possible to give details of the constitutive equations used in the mathematical models, which can be found in PhD theses by Hans [7], Quatravaux [8] and Revil-Baudard [9], nor of their boundary conditions. Briefly, the transient 2D models take into account the coupled transfers of heat, solutes and momentum, under turbulent flow conditions, during the remelting of a cylindrical ingot. The major physical phenomena which are simulated are listed below.

Heat transfer: Heat transfer within the ingot by convection and conduction, heat supplied by the electric arc (VAR) or the plasma torch (PAMCHR), heat content of the liquid droplets (VAR) or the metal flowing from the cold hearth (PAMCHR), dissipation of the latent heat of solidification, heat extraction at the ingot base and edge by :

-contact with the annulus crucible (PAMCHR) or the static mold (VAR),

-radiation towards the chamber wall (PAMCHR) or the static mold through a shrinkage gap (VAR).

Momentum transfer: Natural convection, due to temperature and concentration gradients, self-induced electromagnetic forces, 3-D forced convection related to electromagnetic stirring in VAR, turbulent flow conditions, interaction between the solid and liquid within the mushy zone.

Solute transfer: Transport of solute elements in the melt pool and mushy zone, input of matter at the top of the ingot, evaporation at the VAR free surface, solute redistribution at the solid-liquid interface.

The determination of metal flow in the melt pool and mushy zone is based on solution of the vectorial Navier-Stokes equation, using the continuum mixture theory proposed by Bennon and Incropera [10]. The principal assumptions of this part of the model are the following:

-the two-phase liquid-solid system is considered to be a continuum

-the solidification is columnar

- the mushy zone is assimilated to a porous solid characterized by its permeability

To a first approximation, the permeability is estimated from a Kozeny-Carman relation (1):

$K=K_{0} \frac{g_{l}^{3}}{\left(1-g_{l}\right)^{2}}$

where $\mathrm{K}_{0}$ is a constant related to the characteristic dimensions of the solidification microstructure (mean interdendritic spacings) and gl the liquid fraction. The value of $\mathrm{K}_{0}$ governs the magnitude of the liquid metal movement in the mushy zone and the corresponding macrosegregation during solidification.

At any time during the melting, possible hot-topping and cooling stages, the models compute the melting current density in the ingot, electromagnetic force field, PAMCHR 2-D or VAR 3-D velocity field in the liquid pool and mushy zone, intensity of flow turbulence, temperature and liquid fraction maps in the whole ingot, composition map for any given solute and solidification conditions (thermal gradient at the solidification front, instantaneous cooling rate and local solidification time).

\section{Model validation}

Vacuum Arc Remelting (SOLAR)

The SOLAR model used for the solidification of a Ti64 industrial VAR ingot was already validated by Patel et al. [2] by comparing measured and predicted liquid pool profile of a $914 \mathrm{~mm}$ and $860 \mathrm{~mm}$ test ingot also studied by Bertram et al. [11] and Minisandram et al. [12]. In this study, calculated pool profiles showed good agreement with experimental data. Similar work has been performed at A\&D as a preliminary validation study.

In addition, several EcoTitanium VAR industrial test melts using same operating parameters (melt rate, voltage, current and hot-top profile), were analyzed. Concentrations in $\mathrm{Al}, \mathrm{Fe}, \mathrm{O}$ and $\mathrm{V}$ were has been measured radially (edge, mid-radius and center) at a location corresponding to the ingot top position before start of hot-top. Figure 2 shows the average relative concentration for each alloying element. It can be seen that each element shows a radial variation in accordance with its solidification partition coefficient (see Table 1; $\mathrm{k}<1$ : edge to center segregation for $\mathrm{Fe}$ and $\mathrm{V} ; \mathrm{k}>1$ : center to edge segregation for $\mathrm{Al}$ and $\mathrm{O}$ ). Some depletion of aluminium was measured compared to nominal concentration, due to volatilization during VAR melting. 

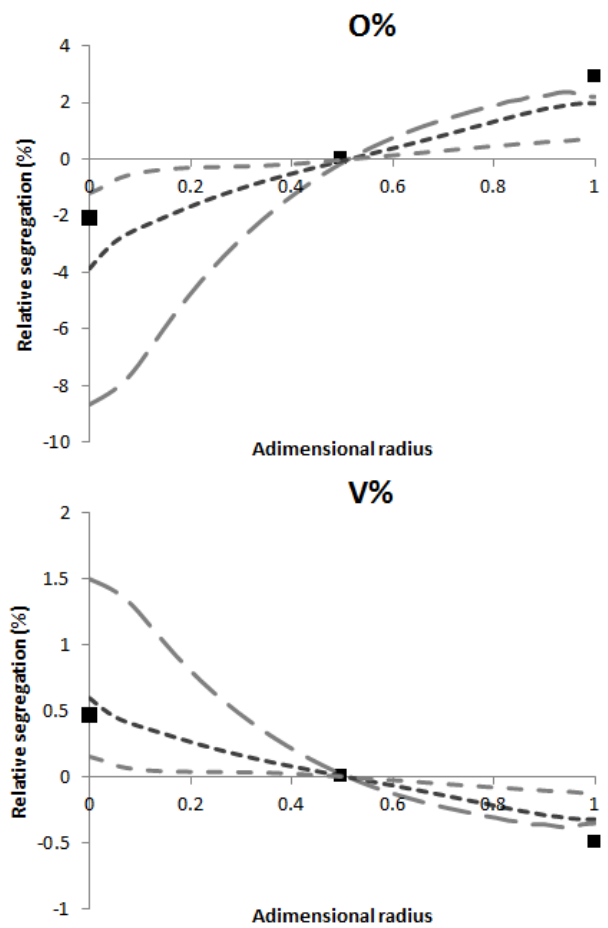

- Exp. data

- $\mathrm{K} 0=\mathrm{E}-9$

- $-\mathrm{K} 0=\mathrm{E}-10$

$-\mathrm{K} 0=\mathrm{E}-11$

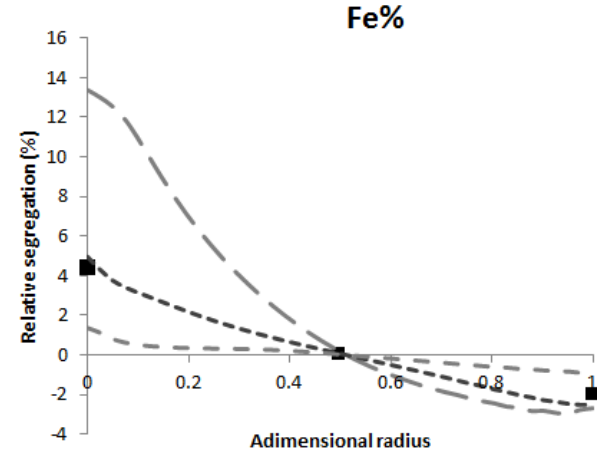

$\mathrm{Al} \%$

- Exp. data

- $\cdot \mathrm{KO}=\mathrm{E}-9$

- $-\mathrm{KO}=\mathrm{E}-10$

$-\mathrm{K} 0=\mathrm{E}-11$

Figure 2: Experimental segregation and results of simulations for three mushy zone permeability constants $K_{0}\left(E^{-9}, E^{-10}\right.$ and $\left.E^{-11} \mathbf{m}^{2}\right)$

Table 1: Partition coefficient of Al, V, Fe, O in Titanium alloys

\begin{tabular}{|c|c|c|}
\hline Elements & Partition Coefficient & Réf. \\
\hline $\mathrm{Al}$ & $1.01-1.13$ & {$[13] /[14]$} \\
\hline $\mathrm{V}$ & $0.89-0.96$ & {$[13] /[14]$} \\
\hline $\mathrm{Fe}$ & $0.38-0.71$ & {$[14] /$ Binary diagram } \\
\hline $\mathrm{O}$ & $1.33-1.60$ & {$[14] /$ Binary diagram } \\
\hline
\end{tabular}

For each alloying element, radial segregation intensity has been defined as the linear regression slope calculated from experimental data. Figure 3 shows segregation intensity as a function of the solidification partition coefficient found in the literature for Ti64 alloy (see Table 1). A clear correlation between segregation intensities and partition coefficients can be seen which indicates that the average measured concentration variation is linked to macrosegregation during solidification.

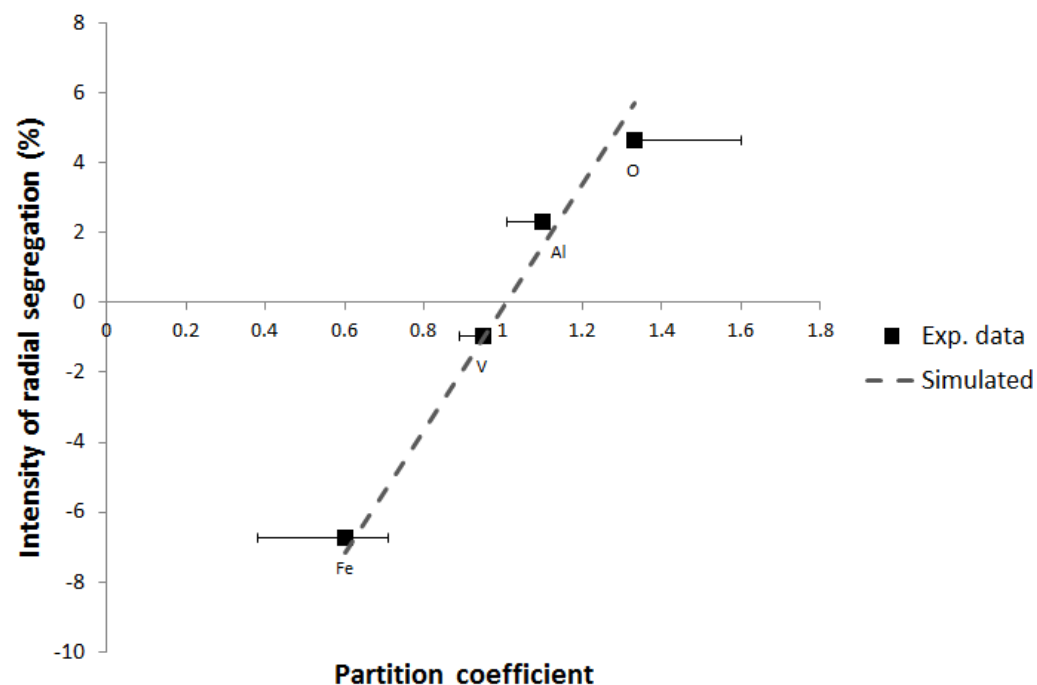

Figure 3: Intensity of radial segregation vs partition coefficient (experimental data and simulation)

Measured radial segregation was compared with SOLAR prediction. In order to determine the appropriate $\mathrm{K}_{0}$ permeability constant (see equation 1 ) of the mushy zone governing the segregation intensity at the ingot scale, a sensibility study has been performed. Three different levels of $\mathrm{K}_{0}$ have been simulated (Figure 2 ), the best result being found for a value of $10^{-10} \mathrm{~m}^{2}$ (Figure 3). Evaporation of aluminium is simulated with a good agreement (Figure 2). 
As a new model, solidification prediction of PAMELA needed to be validated. As for SOLAR, a comparison between experimental data and calculation has been performed. An industrial ingot was melted for this purpose and macroetched longitudinally (Figure 4, A). On the macrograph, pool profiles have been determined using grain orientation (Figure 4, B). Pool shapes and columnar grain appear to be asymmetric due to liquid metal flow from the PAM pour lip on one side of the crucible (about $15 \%$ off axis; Figure $4, \mathrm{~B}$ ). Liquid pool depth is measured on each side of the ingot, below and opposite to the pour lip location (Figure 5) neglecting any liquid metal head. Pool profiles are simulated taking into account ingot melting parameters (melt rate, torch power and yield). The torch yield is estimated to $35 \%$, in accordance with experimental measurement [1], giving the best pool shape description, which is close to the measured pool shape and depth (Figure 6), even if the current 2D model cannot take into account the nonsymmetric enthalpy input from the pour lip (Figure 4, C).
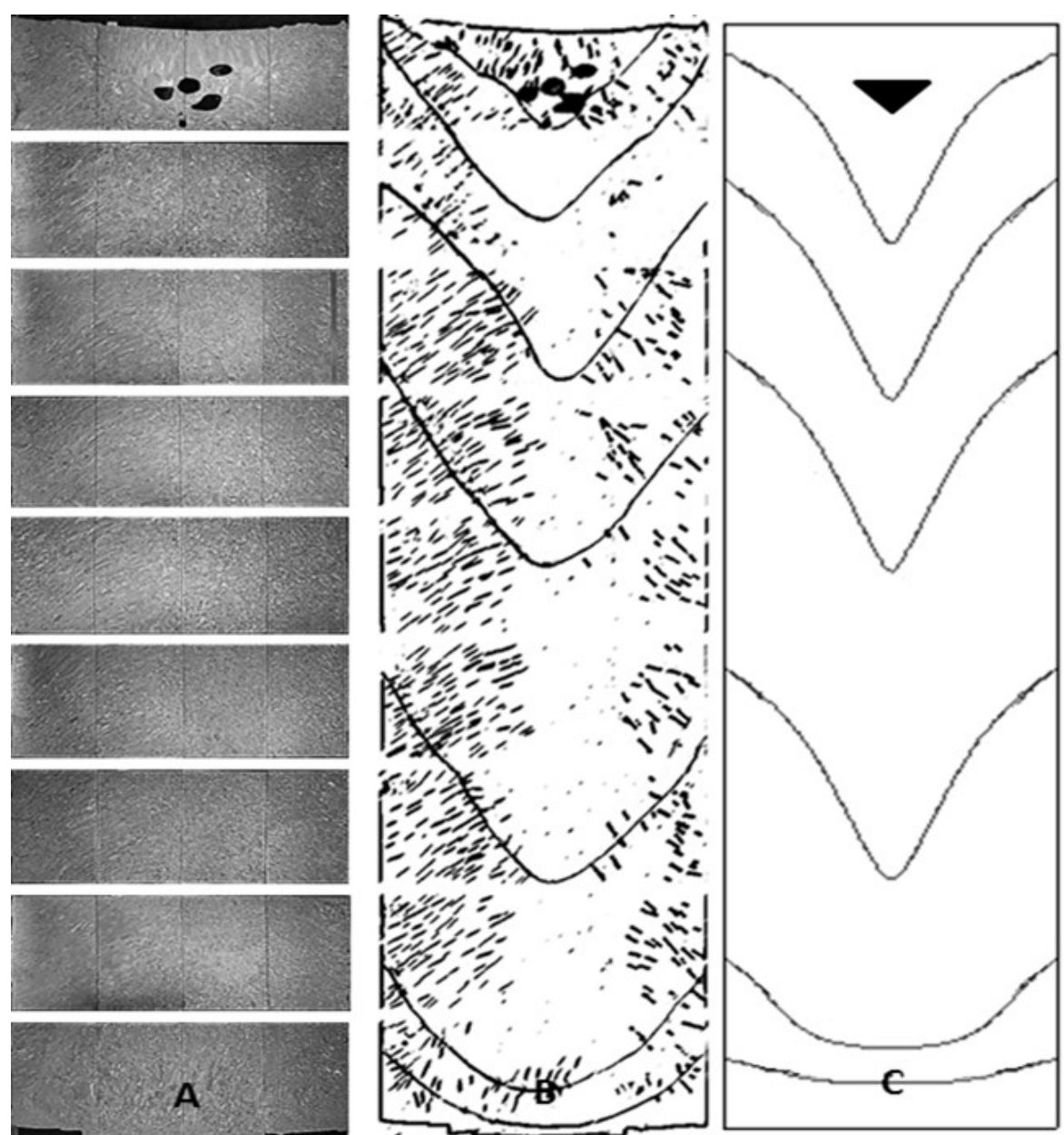

Figure 4: A) Macrographs of the PAM electrode, B) observed pools C) simulated pool profile and cavity position (liquid flow from PAM pour lip located at the right side of macrograph)

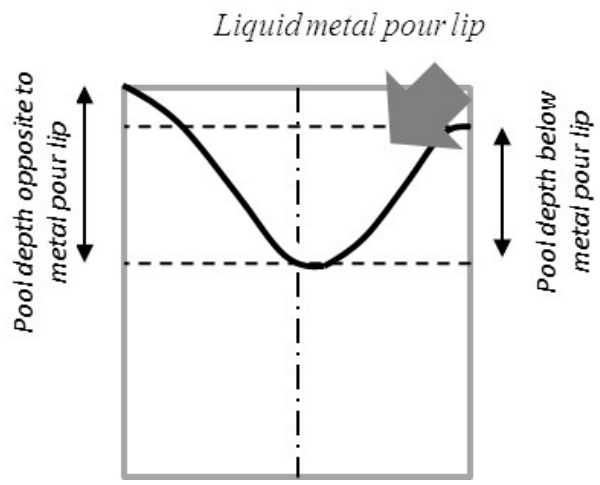

Figure 5: Schematic PAM pool shape in relation with position of liquid metal pour lip 


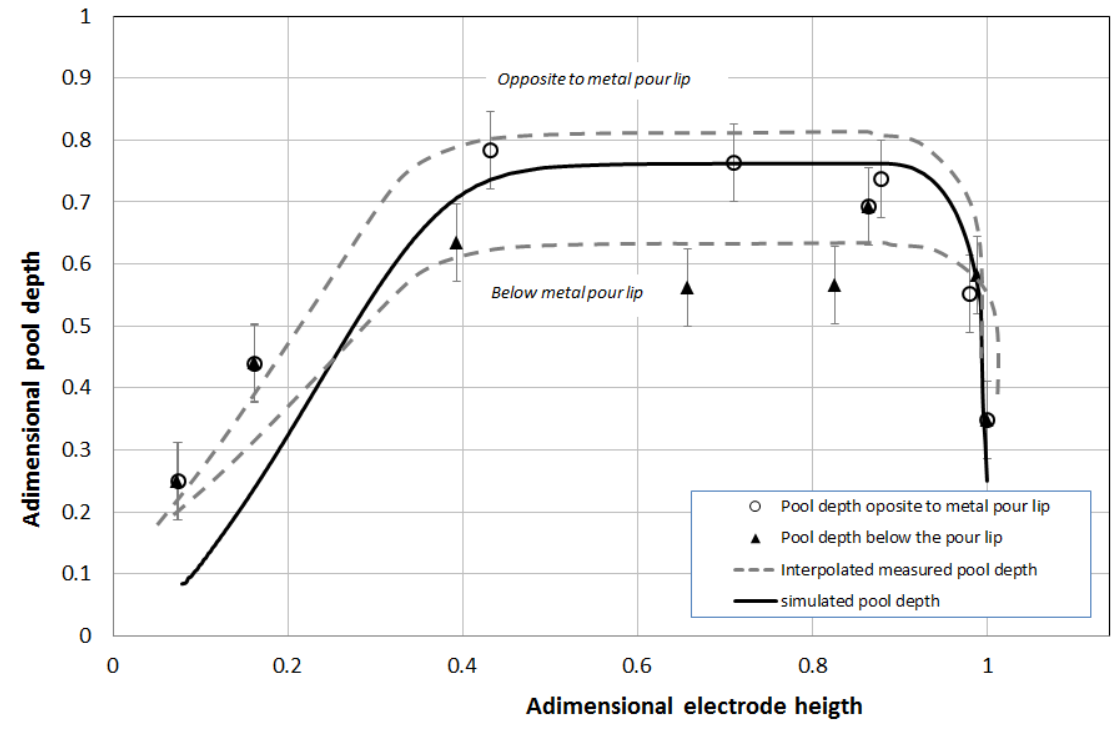

Figure 6 : Comparison between measured pool depth and simulated pool depth

Figure 7 shows the comparison between calculated segregation intensity for the above industrial VAR and PAM test melts. Segregation intensity due to solidification is much lower for PAM than for VAR. This is partly due to lower local solidification time achieved for PAM (-50\%).

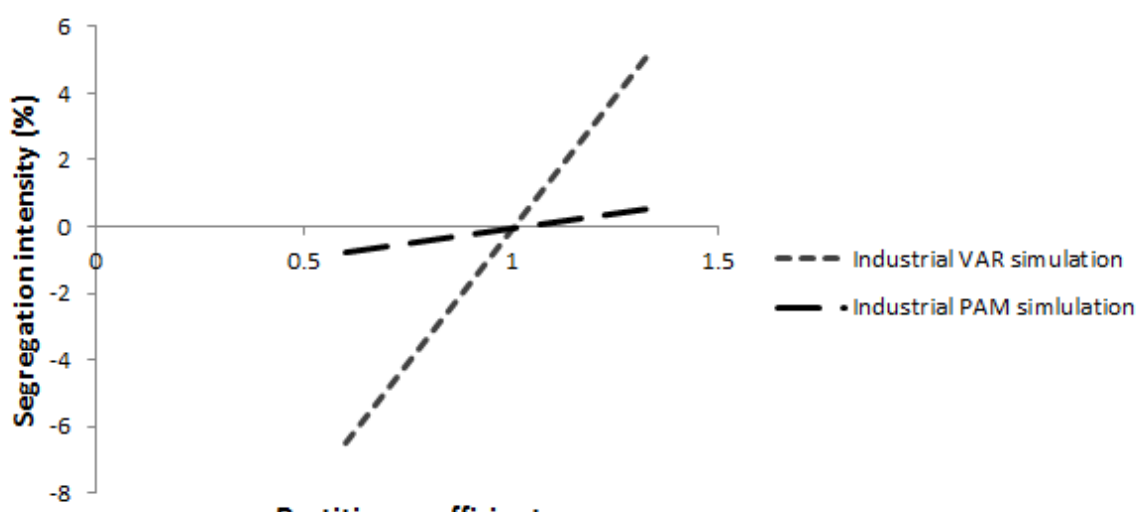

Partition coefficient

Figure 7 : Industrial PAM simulated radial segregation intensity compared to simulated industrial VAR

However the measured concentrations on the industrial PAM show a greater variation compared to the modelling results assuming a feeding of an homogeneous concentration of alloying element. It exhibits another source of possible variation, in addition to segregation during solidification. Chemical inhomogeneity in the PAM melted materials can result in larger variation of radial segregation, mitigation/intensification or even inverse segregation. This feature is illustrated in the study below.

\section{PAM ingot Chemical homogeneity study}

Assessment of PAM ingot chemical homogeneity is useful for developing cost-effective process route using a single melt, to define chemistry requirement for scraps, raw materials, requirement of weighting and blending unit. PAMELA and SOLAR can help to measure process ability to cope with a chemistry deviation.

An example is given here with the response of the PAM casting to a large oxygen chemistry deviation (20\% increases) of the casting feeding liquid metal composition. In our study, mixing in the PAM hearths is neglected (the latter is also very effective to dilute oxygen variation). It is hence a worst case scenario study. Figure 8 (b) shows the oxygen concentration map for an increase corresponding to the casting of one liquid pool volume. The resulting radial segregation (Figure 9 ) can be very complex (positive or negative) depending on the mixing intensity and the liquid pool shape. Three different durations of this deviation, corresponding to the casting of $0.5 / 1 / 2$ liquid pool volume of the PAM ingot, were investigated (Figure 8 (a) (b) (c)). Figure 10 shows the center and mid-radius dilution capacity of the PAM casting. Oxygen increase is spread over some height of the ingot and the maximum oxygen content is close to the theoretical mixing value (50\% dilution for one liquid pool volume of oxygen deviation). The effect of VAR melting of the PAM ingot (after tilting of the electrode) was also investigated. The SOLAR results (Figure 11 (b)) show some additional oxygen dilution. However it can be seen that centre to edge oxygen segregation is more intense after VAR than after PAM. 

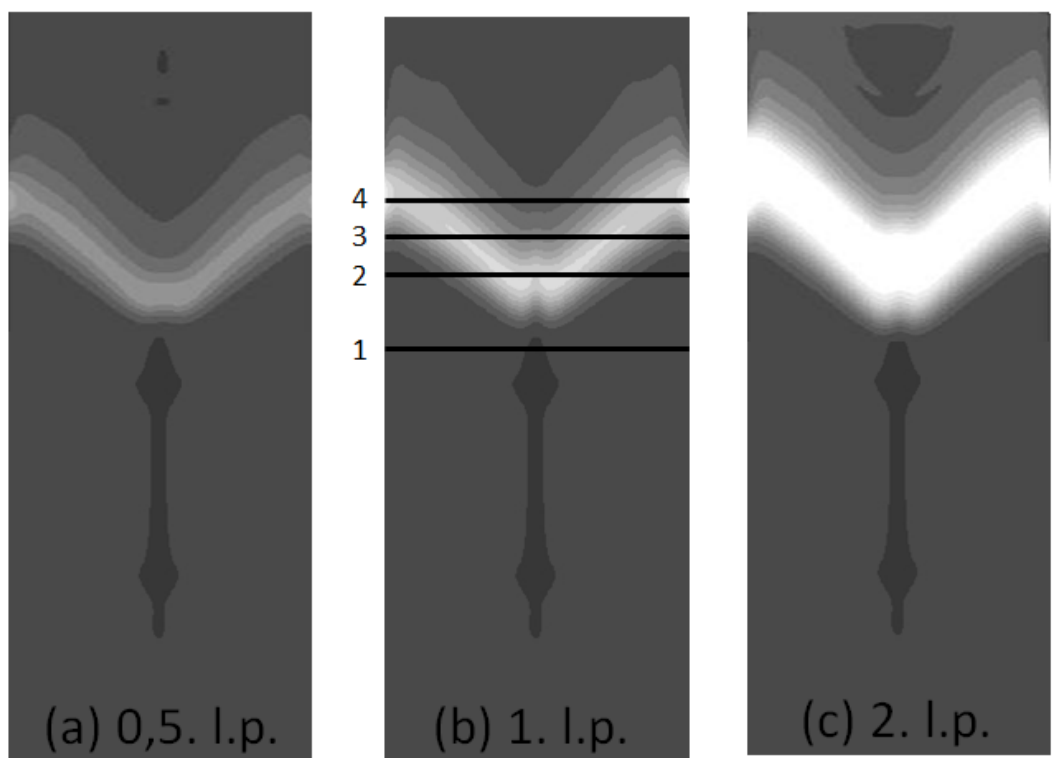

Top

Figure 8: Oxygen concentration map for the three cases (a) 0.5 liquid pool, (b) 1 liquid pool, (c) 2 liquid pool

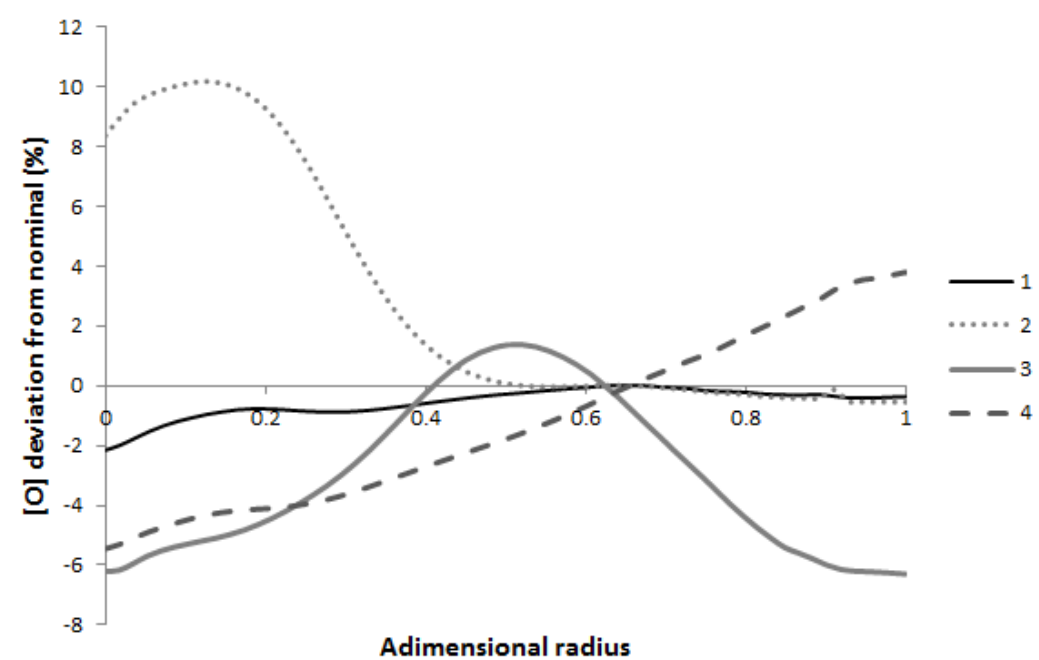

Figure 9: PAM ingot calculated radial oxygen segregation (at different heights labeled on Figure 8 (b))

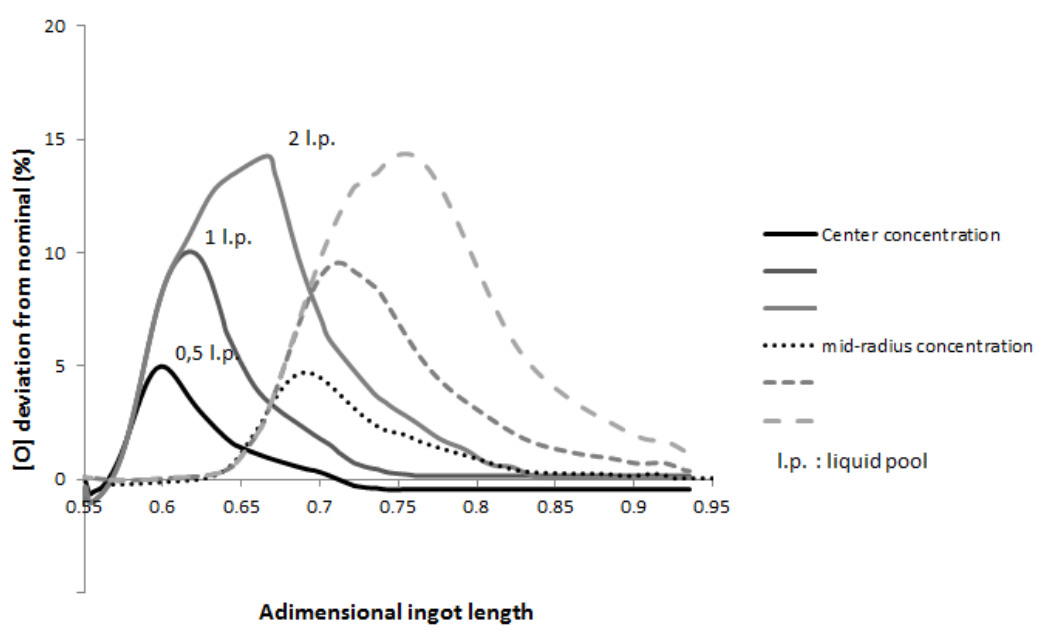

Figure 10: Calculated centre and mid-radius oxygen content of the PAM ingot for a $20 \%$ increase of oxygen content of the feeding liquid metal during 0.5 / 1 / 2 liquid pool volume casting 

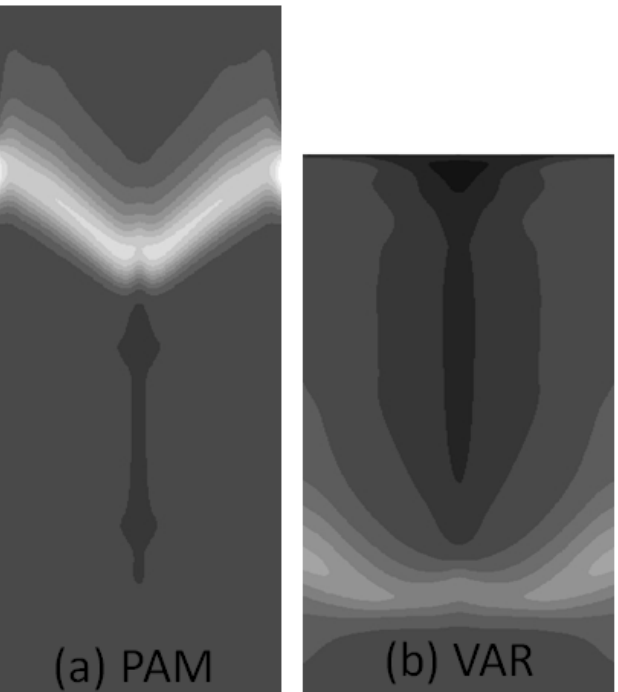

Top

Figure 11 : Calculated oxygen content map in the PAM ingot (a) and VAR ingot (b) (after melting the reversed PAM ingot)

\section{Conclusion}

The use of solidification models for the PAMCHR casting and the VAR remelting, which are operational at an industrial scale for predicting melt pool profile, macrosegregation and mixing ability, was presented. Both VAR and PAMCHR casting model have been validated through comparison with experimental data. An industrial PAMCHR ingot was macroetched for pool depth determination. Results show a good agreement with the prediction. In addition the macrosegregation behavior for Ti64 was well described after optimization of the mushy zone permeability constant.

The two models were used to study alloying elements behavior during casting. PAM and VAR can help minimizing alloy content variation by mixing in the liquid pool. The obtained radial segregation pattern can be complex (positive or negative) depending on the interaction between solute concentration and liquid pool shape. VAR remelting of the PAM ingot increases mixing capability but leads to higher final segregation due to solidification. Hence single PAM seems to be a good alternative for the casting of segregation sensitive alloys or reduced cost Ti64 [15]

[1] L. Décultot, S. Hans, E. Doridot, J. Delfosse, F. Ruby-Meyer and J.-P. Bellot : Titanium 2019 Proceedings, 2019.

[2] A. Patel, D. W. Tripp et D. Fiore: Proc. Int. Symp. on "Liquid Metal Processing and casting", 2013.

[3] A. Jardy, S. Hans et D. Ablitzer : Proc. Int. Symp. on "Liquid Metal Processing and casting", 1994

[4] T. Quatravaux, S. Ryberon, S. Hans, J. Alain, B. Lusson, P.-E. Richy and D. Ablitzer: Journal of Materials Science, 39, 124, pp. 7183-7191, 2004.

[5] A. Jardy and D. Ablitzer: Materials science and Technology, 25, 12, pp. 163-169, 2009.

[6] M. Revil-Baudard, A. Jardy, H. Combeau, F. Leclerc and V. Rebeyrolle : Metallurgical and Materials Transactions B, 45, 11, pp. 51-57, 2014.

[7] S. Hans, PhD thesis, INPL, Nancy, France, 1995

[8] T. Quatravaux, PhD thesis,INPL, Nancy, France, 2004.

[9] M. Revil-Baudard, PhD thesis, UL, Nancy, France, 2012.

[10] W. Bennon and F. Incropera: International Journal of Heat and Mass Transfer, 30, 110, pp. 2161-2170, 1987.

[11] L. A. Bertram, P.R. Schunk, S.N. Kempka, F. Spadafora and R. Minisandram, JOM, pp. 18-21, 1998

[12] L. Nastac, Y. Pang and C.E. Shamblen: AFS Transactions , 101-031, pp. 27-41, 2001.

[14] A. Kawakami, Master thesis, UBC, Vancouver, 2002.

[15] J.Lecadet, R. Forestier, P. Delaborde: Titanium 2019 Proceedings, 2019. 